\title{
A empregabilidade da pasta CTZ no tratamento endodôntico da dentição decídua:
} uma revisão bibliográfica

The employability of $\mathrm{CTZ}$ paste in the endodontic treatment of primary dentition: a literature review

La empleabilidad de la pasta CTZ en el tratamiento endodóntico de la dentición temporal: revisión de la literatura

Thirza Keanne Nunes Lindoso ORCID: https://orcid.org/0000-0002-8215-2651 Faculdade Pitágoras de São Luís, Brasil E-mail: thurza.nunes166@hotmail.com

Wendel Chaves Carvalho

ORCID: https://orcid.org/0000-0001-8345-366X Faculdade Pitágoras de São Luís, Brasil E-mail: wendelchavescarvalho@ hotmail.com

Caroline Rodrigues Thomes ORCID: https://orcid.org/0000-0003-3522-5368

Universidade Federal do Espírito Santo, Brasil

E-mail: carolthomesoodonto@gmail.com

Dara Lourenna Silva da Nóbrega ORCID: https://orcid.org/0000-0003-3522-5368 Faculdade Pitágoras de São Luís, Brasil

E-mail: daranobrega26@gmail.com

Roberta Del Piero Teixeira

ORCID: https://orcid.org/0000-0001-6077-6239

Universidade Federal do Espírito Santo, Brasil

E-mail: robertadelpiero@outlook.com

Élida Cardoso da Silva Lima

ORCID: https://orcid.org/0000-0002-5130-9273

Faculdade Pitágoras de São Luís, Brasil

E-mail: elidacardoso514@gmail.com

Watuzi Barbosa de Melo

ORCID: https://orcid.org/0000-0002-4094-6752 Faculdade Pitágoras de São Luís, Brasil

E-mail: tuzidemelo@gmail.com

Maria Fernanda Souza

ORCID: https://orcid.org/0000-0003-3292-1659 Faculdade Pitágoras de São Luís, Brasil E-mail: mf_fernanda1@ @otmail.com

Meirileide Marinho Barros

ORCID: https://orcid.org/0000-0002-7960-1620 Faculdade Pitágoras de São Luís, Brasil E-mail: meiri.marinho@yahoo.com.br

Israel Fillipe Fontes de Oliveira

ORCID: https://orcid.org/0000-0003-3522-5368 Faculdade Pitágoras de São Luís, Brasil

E-mail: israelfilippe7@gmail.com

André Almeida Antunes

ORCID: https://orcid.org/0000-0003-3522-5368

Centro Universitário de Belo Horizonte, Brasil

E-mail: andredemu@yahoo.com.br

Welen Rocha Marques

ORCID: https://orcid.org/0000-0003-3522-5368 Faculdade Pitágoras de São Luís, Brasil

E-mail:wrocha629@gmail.com

Antonio Fabricio Alves Pereira

ORCID: https://orcid.org/0000-0003-3522-5368 Faculdade Pitágoras de São Luís, Brasil

E-mail: antoniofabricio.af@outlook.com 


\author{
Ludmila Serrão Lobato \\ ORCID: https://orcid.org/0000-0002-9957-9483 \\ Faculdade Pitágoras de São Luís, Brasil \\ E-mail: ludy_milla30@hotmail.com \\ Thiago Carvalho Farias \\ ORCID: https://orcid.org/0000-0002-4704-8058 \\ Faculdade Pitágoras de São Luís, Brasil \\ E-mail: thiagofariascg@gmail.com \\ Luana Martins Cantanhede \\ ORCID: https://orcid.org/0000-0002-8419-9269 \\ Universidade Federal do Maranhão, Brasil \\ E-mail: luanacantanhede@hotmail.com
}

\begin{abstract}
Resumo
Objetivos: O objetivo desse estudo foi descrever as vantagens e desvantagens da pasta CTZ para o tratamento endodôntico de dentes decíduos. Revisão de literatura: Os canais radiculares de dentes decíduos, têm características peculiares, que dificultam o acesso e a instrumentação, como: curvaturas acentuadas e altos índices de presença de canais acessórios. Os materiais obturadores utilizados na terapêutica endodôntica dos dentes decíduos precisam ser reabsorvíveis, antimicrobianos, possibilitar preenchimento e adesão às paredes dos canais radiculares, e devem ser de fácil remoção, características essas que possibilitam um não comprometimento para a dentição permanente futura da criança. A técnica de aplicação da pasta CTZ (cloranfenicol, tetraciclina e óxido de zinco eugenol) é considerada fácil, simples e pode ser realizada em uma única sessão, possui poder antibacteriano, promovendo a estabilização da reabsorção óssea e não causando sensibilidade tecidual. Além disso, ela não necessita de instrumentação prévia do canal radicular, independentemente do diagnóstico pulpar. Considerações finais: $\mathrm{O}$ tratamento endodôntico realizado na dentição decídua apresenta diversas limitações, como a sua anatomia e a dificuldade de execução de um tratamento invasivo em um paciente pediátrico. A utilização da pasta CTZ na terapêutica pulpar de dentes decíduos possibilita a manutenção dos dentes tratados endodonticamente, não oferecendo danos aos seus sucessores permanentes, por isso o seu uso se torna uma opção de tratamento pulpar na odontopediatria, entretanto, são necessários mais estudos que possam trabalhar a efetividade dessa pasta obturadora a longo prazo, ajudando a desmistificar tal acompanhamento.
\end{abstract}

Palavras-chave: Endodontia; Odontologia; Odontopediatria; Terapêutica.

\begin{abstract}
Objectives: The aim of this study was to describe the advantages and disadvantages of CTZ paste for the endodontic treatment of primary teeth. Literature review: Root canals of deciduous teeth have peculiar characteristics that make access and instrumentation difficult, such as: accentuated curvatures and high rates of accessory canals. The filling materials used in the endodontic treatment of primary teeth need to be reabsorbable, antimicrobial, allow filling and adhesion to the walls of the root canals, and must be easy to remove, characteristics that allow non-compromising for the child's future permanent dentition. The technique of applying CTZ paste (chloramphenicol, tetracycline and zinc oxide eugenol) is considered easy, simple and can be performed in a single session, has antibacterial power, promoting stabilization of bone resorption and not causing tissue sensitivity. Furthermore, it does not require previous instrumentation of the root canal, regardless of the pulp diagnosis. Final considerations: The endodontic treatment performed in primary dentition has several limitations, such as its anatomy and the difficulty of performing an invasive treatment in a pediatric patient. The use of CTZ paste in pulp therapy for primary teeth allows the maintenance of endodontically treated teeth, without harming their permanent successors, so its use becomes an option for pulp treatment in pediatric dentistry, however, further studies are needed. work on the effectiveness of this obturator paste in the long term, helping to demystify such monitoring.
\end{abstract}

Keywords: Endodontics; Dentistry; Pediatric Dentistry; Therapy.

\title{
Resumen
}

Objetivos: El objetivo de este estudio fue describir las ventajas y desventajas de la pasta CTZ para el tratamiento endodóntico de dientes temporales. Revisión de la literatura: Los conductos radiculares de los dientes temporales tienen características peculiares que dificultan el acceso y la instrumentación, tales como: curvaturas acentuadas y altas tasas de conductos accesorios. Los materiales de obturación utilizados en el tratamiento endodóntico de los dientes temporales deben ser reabsorbibles, antimicrobianos, permitir el empaste y la adhesión a las paredes de los conductos radiculares, y deben ser fáciles de retirar, características que permitan no comprometer la futura dentición permanente del niño. La técnica de aplicación de pasta CTZ (cloranfenicol, tetraciclina y óxido de zinc eugenol) se considera fácil, simple y se puede realizar en una sola sesión, tiene poder antibacteriano, favorece la estabilización de la resorción ósea y no provoca sensibilidad tisular. Además, no requiere instrumentación previa del conducto radicular, independientemente del diagnóstico pulpar. Consideraciones finales: El tratamiento de endodoncia realizado en dentición temporal tiene varias limitaciones, como su anatomía y la dificultad de realizar un tratamiento invasivo en un paciente pediátrico. El uso de pasta CTZ en terapia pulpar para dientes temporales permite el mantenimiento de dientes tratados endodónticamente, sin dañar a sus sucesores permanentes, por lo que su uso se convierte en una 
opción para el tratamiento pulpar en odontopediatría, sin embargo, se necesitan más estudios. esta pasta de obturador a largo plazo, ayudando a desmitificar dicho seguimiento.

Palabras clave: Endodoncia; Odontología; Odontología Pediatrica; Terapia.

\section{Introdução}

O papel da odontologia é assegurar a manutenção da dos dentes decíduos em bom estado até que ocorra a sua esfoliação fisiológica, levando em consideração a importância a presença dos dentes decíduos no arco dentário para que seja mantido o espaço adequado, servindo de guia para o irrompimento dos dentes permanentes. Além de serem de extrema importância para estética, fonética, mastigação e bem-estar psicossocial e emocional da criança (Sousa; Duarte, Sousa, 2014; Siegl et al., 2015; Reis et al., 2016). Entretanto, por conta das suas características fisiológicas, eles são mais propícios a cárie, que podem facilmente alcançar o tecido pulpar (Reis et al., 2016).

Considerando as limitações apresentadas pelos dentes decíduos, algumas características anatômicas dos mesmos devem ser notadas, como a conformação dos canais radiculares com curvatura acentuada, além de grande quantidade de canais acessórios e o processo de rizólise de maneira irregular, comportamento da criança, dentre outros considerados importantes nessa etapa (Reis et al. 2016; Sousa; Duarte; Sousa, 2014; Moura et al., 2016). Assim, por conta dessas limitações, muitas crianças são submetidas a extrações precoces (Moura et al., 2016). Além disso, a terapia pulpar realizada em dentes decíduos, também pode ser complexa considerando outros motivos, como a dificuldade que aparece na condução do comportamento da criança, as diferenças na morfologia dos dentes, a complexidade dos canais radiculares, a incerteza do processo de reabsorção das raízes e as dificuldades em colocar o material no interior dos canais radiculares (Raslan, Mansour \& Assfoura, 2017) e deve-se buscar avaliar a capacidade de redução microbiana e fornecer orientação na seleção de instrumentos adequados pelo cirurgião-dentista, diminuindo as falhas endodônticas e reduzindo o tempo de trabalho (Fonseca et al., 2020).

Para que a saúde da dentição decídua possa ser restabelecida e suas funções mastigatórias, fonéticas e estéticas sejam mantidas, o tratamento endodôntico dos dentes decíduos está indicado. Dentre os requisitos para a resolução do tratamento pulpar, deve-se notar que a instrumentação e irrigação dos canais radiculares são importantes, mas quando essa alternativa não for possível, torna-se necessária uma efetiva medicação intracanal, com o intuito de promover a reparação tecidual, por meio de sua ação antimicrobiana (Reis et al., 2016). Dentre as terapias pulpares utilizadas, destaca-se a pasta antibiótica CTZ (cloranfenicol, tetraciclina e óxido de zinco eugenol).

A pasta de CTZ tem sido especialmente indicada em serviços públicos de saúde e em casos de pacientes que não sejam colaborativos, considerando o baixo custo de seus componentes, fácil manipulação, compatibilidade biológica, longo tempo de aplicação clínica e os resultados clínicos comprovados. No entanto, ainda existem controversas quanto à segurança no emprego do cloranfenicol (Barros \& Neres, 2017). Além disso, essa técnica não exige a instrumentação dos canais radiculares, prévia ou após a desinfecção, o que confere grande benefício na terapêutica do paciente não colaborador. Todavia, pode apresentar desvantagens, como a pigmentação da coroa dental do dente decíduo tratado e provocar alergia ao paciente sensível a um dos componentes da pasta (Sousa, Duarte \& Sousa, 2014).

Assim, com base no que foi descrito anteriormente, a presente pesquisa tem como objetivo geral descrever as vantagens e desvantagens da pasta CTZ para o tratamento endodôntico de dentes decíduos, abordando: o tratamento endodôntico em dentes decíduos, as propriedades e a composição química da pasta CTZ, as evidências clínicas e a resposta biológica sobre o uso desta pasta no tratamento endodôntico de dentes decíduos. 


\section{Metodologia}

Trata-se de uma revisão bibliográfica narrativa, na qual as buscas bibliográficas se fundamentaram por meio de seleções de artigos publicados em três idiomas: português, inglês e espanhol, que se encontravam disponibilizados no portal eletrônico PubMed, assim como nas bases de dados Google Acadêmico, Scielo e Periódicos Capes. Além disso, os artigos incluídos foram sem data limite de publicação. Os descritores utilizados em combinação com os operadores booleanos para a pesquisa foram: "Endodontic treatment of deciduous", "Pulpectomy”, indexados no Mesh e "CTZ”, “Terapia pulpar”, "Pulpectomia", indexados no Decs.

Segundo Rother (2007), os artigos de revisão de literatura narrativa constituem publicações amplas, consideradas apropriadas para a descrição e discussão do desenvolvimento ou até mesmo o "estado da arte" de um determinado assunto, sob ponto de vista teórico ou contextual. Além disso, essa categoria de artigos apresentam um papel relevante para a educação continuada, considerando que permitem ao leitor adquirir e atualizar o conhecimento acerca de uma temática específica em curto espaço de tempo. Todavia, não possuem metodologia que permitam a reprodução dos dados e nem fornecem respostas quantitativas para questões específicas.

A seleção dos estudos para a realização desta pesquisa foi feita a partir dos títulos e resumos. Os critérios de inclusão que nortearam a busca foram trabalhos que com relevância e relação com a pesquisa que foi realizada, que tratassem da temática de tratamentos endodônticos exclusivamente na dentição decídua em pacientes humanos. A pesquisa incluiu estudos clínicos, relatos de casos, estudos comparativos, observacionais e literatura cinza (monografias, teses e dissertações). Foram excluídos estudos com animais, laboratoriais, epidemiológicos, editoriais e trabalhos publicados em anais de eventos. Aqueles estudos que abordassem a dentição permanente como tema principal também foram descartados da pesquisa.

\section{Resultados}

\section{Tratamento endodôntico em dentes decíduos e materiais obturadores utilizados}

A lesão cariosa ainda é o principal motivo da perda precoce dos dentes decíduos, apesar de inúmeros avanços na promoção da saúde. Em segundo lugar, os traumatismos dentoalveolares também podem comprometer a permanência do elemento dental na cavidade bucal. Nesse sentido, essas e outras situações podem levar a danos irreversíveis do tecido pulpar, tornando necessária a recorrência ao tratamento endodôntico em casos onde for possível a manutenção do dente no arco, para que seja restabelecida a sua integridade (Silva \& Silva, 2018).

A terapêutica endodôntica é indicada para que a dentição decídua seja restabelecida, de forma a as funções mastigatórias, fonéticas e estéticas. Nota-se que para a resolução do tratamento endodôntico em dentes decíduos, a instrumentação e irrigação dos canais radiculares se tornam requisitos para o sucesso e longevidade do tratamento, mas quando não for possível, a empregabilidade da medicação intracanal é necessária no alcance da reparação tecidual, por meio das suas ações terapêuticas antimicrobianas e biológicas (Reis et al., 2016). Além disso, os canais radiculares de dentes decíduos, têm características peculiares, que dificultam o acesso e a instrumentação, como: curvaturas acentuadas e altos índices de presença de canais acessórios (Toledo \& Massara, 2010). Dessa maneira, a instrumentação é considerada como uma etapa importante do tratamento endodôntico e a escolha do instrumental deve ser realizada com o intuito de garantir maior segurança ao operador e paciente, maior agilidade e efetividade na realização do procedimento (Toline, Bresolin \& Shitsuka, 2021).

Dessa maneira, os materiais obturadores utilizados na terapêutica endodôntica dos dentes decíduos precisam ser reabsorvíveis, antimicrobianos, possibilitar preenchimento e adesão às paredes dos canais radiculares, e devem ser de fácil remoção, características essas que possibilitam um não comprometimento para a dentição permanente futura da criança (Lima, 2019). Nesse sentido, Guedes e colaboradores (2012) inferiram que um material obturador radicular ideal deve possuir as 
seguintes características: anti-inflamatório, bactericida, bacteriostático, estável, radiopaco, reabsorvível e biocompatível, além de possibilitar condições de reparo. Dentre os materiais obturadores utilizados no tratamento endodôntico de dentes decíduos estão: as pastas a base de hidróxido de cálcio, pastas iodoformadas e pastas a base de óxido de zinco e eugenol (Guedes-Pinto, 2010).

O hidróxido de cálcio é definido como um material obturador para dentes decíduos que se mostra radiopaco, de fácil aplicação e não apresenta toxicidade em relação aos dentes sucessores permanentes (Silva \& Silva, 2018). Segundo Júnior (2017) e Cunha, Barcelos \& Primo (2005), esse material têm demonstrado inúmeros resultados satisfatórios, pois atende às exigências quanto a sua biocompatibilidade, além de induzir a formação de dentina e não modificar a cor do elemento dental.

Segundo Júnior (2017), materiais a base de Óxido de Zinco e Eugenol são bastante utilizados no tratamento de dentes decíduos, pois possuem um satisfatório poder antimicrobiano,apesar de não serem considerados histologicamente biocompativeis. Seguindo essa linha de raciocínio, de acordo com Reis et al. (2016), ele provoca inibição contra o Streptococcus mutans, no qual indica uma possível prevenção contra cárie secundária. Outro material utilizado para a obturação dos canais radiculares dos dentes decíduos é a pasta Kri que possui em sua composição o iodofórmio, paramonoclorofenol canforado e mentol, na qual possui uma possível ação bactericida, fácil inserção, rápida reabsorção, não prejudica os permanentes sucessores e etc, afirmam Júnior (2017) e Cunha, Barcelos \& Primo (2005). Porém, segundo Guedes-Pinto (2016), apesar dos sucessos trazidos na literatura sobre essa pasta, dentro dos critérios de inclusão não foram artigos suficientes para ser indicada na terapêutica endodôntica de dentes decíduos.

As pastas iodoformadas têm apresentado um alto índice de sucesso nos casos de pulpectomia e na obturação de dentes com polpa mortificada apresentando ou não lesão periapical segundo Calixto-Chanca, Correa-Olaya \& Anchelia-Ramírez (2014), além de se apresentarem altamente radiopacas, o que otimiza a coloração após o tratamento realizado (Toledo \& Massara, 2010). De acordo com Júnior (2017), a ligação do iodofórmio com o hidróxido de cálcio em um material obturador tem um efeito de potencializar suas ações, porém nem sempre a ação é benéfica, como é o caso da pasta Vitapex, na qual:

Sua composição é feita de hidróxido de cálcio e iodofórmio, possui uma boa resposta ao tecido radicular, porém apresenta uma coloração amarelada na coroa do dente em um período de tempo após sua utilização por causa da presença do iodo, a pasta possui ação antibacteriana e antimicrobiana (Santos et al., 2013).

Sob outra ótica, a pasta Guedes-Pinto, uma das mais utilizadas na odontopediatria, é composta segundo Júnior (2017) e Santos et al. (2013), por Ricofort (predinisona e rifamicina), Iodofórmio e Paramonoclorofenol Canforado, possui fácil absorção e reabsorção do medicamento aos canais, além de ser antimicrobiana, antisséptica e anti-inflamatória, bactericida e bacteriostática, biocompatibilidade aos canais radiculares e não causa danos ao permanente sucessor. Porém, segundo Piva, Júnior \& Estrela (2005), a pasta apresenta uma forte coloração e a presença de iodofórmio em sua composição faz com que ela promova certo escurecimento da estrutura dentária remanescente.

\section{Composição e propriedades da pasta CTZ}

A pasta antibiótica CTZ foi sugerida em 1959 por Soller (endodontista) e Cappiello (odontopediatra) visando o tratamento de molares decíduos com comprometimento pulpar. A sua composição apresenta a mesma proporção de cloranfenicol, tetraciclina e óxido de zinco e eugenol, sendo este último adicionado durante o ato operatório (Pinheiro et al., 2013). Segundo Barros \& Neres (2017), a pasta CTZ apresenta vantagens em relação as outras pastas obturadoras utilizadas em odontopediatria, pois têm propriedade antibacteriana e antimicrobiana, o que resulta em grandes taxas de sucesso, pois inibe o crescimento microbiano, é de fácil aplicação, além de ser uma técnica minimamente invasiva, possui baixo custo quando comparadas às técnicas convencionais dos tratamentos pulpares e promove a estabilização da reabsorção óssea.

A técnica de aplicação da pasta CTZ (cloranfenicol, tetraciclina e óxido de zinco eugenol) é considerada fácil, simples 
e pode ser realizada em uma única sessão, possui poder antibacteriano, promovendo a estabilização da reabsorção óssea e não causando sensibilidade tecidual. Além disso, ela não necessita de instrumentação prévia do canal radicular, independentemente do diagnóstico pulpar, oferecendo uma grande vantagem no tratamento de pacientes não cooperativos, facilitando o manejo do comportamento do paciente pediátrico e, consequentemente, reduzindo o tempo operatório (Luengo-Ferreira et al., 2019).

Apesar de apresentar inúmeras vantagens que foram anteriormente descritas, a pasta CTZ demonstra uma desvantagem estética que é o escurecimento da coroa dentária promovido pela presença da tetraciclina (Barros; Neres, 2017; Pinheiro et al., 2013; Reis et al., 2016). Para Guedes-Pinto (2016), além de apresentar seu uso discutido em pulpotomias de dentes decíduos devido aos efeitos adversos ocasionados pela presença do cloranfenicol que seriam: "alterações no sangue periférico, leucocitose, linfócitos atípicos e granulações tóxicas" (Barros \& Neres, 2017). Em contrapartida, Segundo Piva, Junior \& Estrela (2009), a pasta CTZ deve ser utilizada levando em consideração o fato de seu uso ocorrer há bastante tempo (desde 1964), em várias universidades do Brasil, demonstrando resultados bem satisfatórios e sem comprovação direta de que seus componentes estejam associados a alguma doença causada pelo seu uso.

Além disso, o sucesso clínico da pasta CTZ é atribuído ao fato de que em dentes decíduos, a presença de canais acessórios, porosidade e permeabilidade na região do assoalho pulpar indica a existência de uma provável conexão entre o tecido pulpar e tecidos periodontais, fazendo com que a combinação de medicamentos antibacterianos pode se dissipar nessas regiões reduzindo o número de microrganismos (Luengo-Ferreira et al., 2016). Soma-se isso ao fato de que o processo de calcificação dos dentes permanentes termina entre os 7 e 8 anos de idade, evidenciando que a partir dessa idade não existem mais riscos de manchas na dentição permanente (Sousa, Duarte \& Sousa, 2014).

\section{Descrição da técnica endodôntica que utiliza a pasta CTZ}

A pasta CTZ é uma opção terapêutica de material obturador considerado inovador, para o tratamento endodôntico da dentição decídua, por apresentar várias vantagens e boa longevidade para um bom resultado do tratamento, de maneira a conciliar a redução do tempo de trabalho clínico e o conforto para o paciente. A sua utilização é realizada com base em uma técnica de não instrumentação dos canais radiculares, sendo considerada como uma técnica minimamente invasiva, de fácil aplicação e que pode serrealizada em sessão única, o que se torna uma condição ideal para pacientes pediátricos que na maioria das vezes não colaboram com o atendimento, além de promover ação antibacteriana e reabsorção óssea (Barros \& Neres, 2017; Pinheiro et al., 2013; Reis et al., 2016).

Segundo Imparato et al. (2017), a técnica em que a pasta CTZ é utilizada no tratamento endodôntico na dentição decídua é a seguinte:

1. Radiografia Inicial;

2. Anestesia e isolamento do campo operatório;

3. Remoção dos tecidos necrosados com colheres de dentina e/ou brocas de baixa rotação e limpeza da cavidade com solução salina;

4. Remoção do teto da câmara pulpar e de restos pulpares. Lavagem da câmarapulpar com solução salina;

5. Localização e desobstrução dos canais radiculares;

6. Limpeza final da câmara coronária com solução salina e secagem com bolinhas dealgodão estéreis;

7. Preparo da pasta CTZ: manipulação do pó da pasta CTZ com eugenol;

8. Inserção da pasta CTZ e pressão leve com bolinhas de algodão; 
9. Proteção da pasta CTZ com camada fina de guta-percha em bastão. A guta-perchadeve ser colocada levemente aquecida e acondicionada no assoalho da câmara pulpar e entrada dos canais radiculares delicadamente com um condensador de amálgama;

10. Restauração;

11. Radiografia final.

\section{Evidências clínicas e resposta biológica da utilização da pasta CTZ no tratamento endodôntico em dentes decíduos}

Existem diversas opções de materiais que podem ser utilizadas no tratamento endodôntico de dentes decíduos descritos na literatura. No que se tangem os avanços tecnológicos, houve uma simplificação dos procedimentos endodônticos em relação à técnica rotatória, por exemplo. No entanto, o bom tratamento também depende da redução ou eliminação do agente infeccioso, instrumentação apropriada, irrigação eficiente e materiais antibacterianos compatíveis com o material obturador, além do conhecimento de cada caso (Hecksher et al. 2019). Dentro dessa perspectiva, vários estudos descritos a seguir têm demonstrado que a pasta CTZ (cloranfenicol, tetraciclina, óxido de zinco eugenol) têm aplicação fácil, simples e que pode ser realizada em uma sessão, além de apresentar alto poder antibacteriano, promover a estabilização da reabsorção óssea e não causar sensibilidade aos tecidos (Luengo-Ferreira et al., 2019).

Conforme um estudo realizado por Passos, Melo \& Moreira (2008), foi demonstrado que a pasta CTZ obteve sucesso tanto clínico como radiográfico após 14 meses de proservação após ser realizado o tratamento endodôntico em dentes decíduos, tendo como resultado ausência de dor e recidiva da lesão. Com o mesmo objetivo do autor anterior, Oliveira e colaboradores (2019), realizaram um estudo de três casos de pulpotomias tratadas com a pasta CTZ, fazendo o acompanhamento clinico e radiográfico, na qual o material se mostrou satisfatório e efetivo posteriormente a trinta dias da sua realização: não apresentando fístula, abcesso, reabsorção interna e externa, mobilidade, dor e reabsorção óssea com regressão de lesão.

Oliveira \& Costa (206) destacaram que o tratamento pulpar de dentes decíduos com a pasta CTZ podia ser realizado tanto em casos de biopulpectomias quanto em casos de necropulpectomias, ressaltando-se a importância de se realizar um bom diagnóstico das condições pulpares para a escolha da técnica a ser feita. Ainda de acordo com os estudos de Oliveira e Costa (2006), nos casos de biopulpotomias realizadas com a pasta CTZ não se observava nenhuma forma de alteração clínica ou radiográfica. Já nas necropulpectomias verificou-se resultados clínicos e radiográficos satisfatórios em curto prazo, como o desaparecimento de fístula e dor e a retomada da função mastigatória.

Moura e demais autores (2016) realizaram um estudo que teve como objetivo verificar a biocompatibilidade da pasta CTZ, por meio do tratamento de 38 molares decíduos com polpa necrosada com a pasta CTZ, cuja composição é a base de antibióticos. Ao fim do estudo, eles obtiveram a conclusão de que a pasta CTZ é uma opção terapêutica para o tratamento pulpar de molares decíduos, por conta de seu sucesso clinico de 100\% e o sucesso radiográfico de $93 \%$.

Outro estudo que obteve sucesso no seu objetivo deter como alternativa a utilização da pasta CTZ no tratamento pulpar foi o de Siegl et al (2015), no qual os autores fizeram uma comparação utilizando duas técnicas de tratamento endodôntico dos dentes decíduos (Guedes - Pinto e CTZ), afim de acompanhar a área radiolúcida formada na região de furca. $\mathrm{O}$ resultado obtido pelos autores em sua pesquisa foi de que as duas pastas tiveram a resposta clinica semelhante, porém a pasta CTZ teve a área radiolúcida diminuída no período de 6 a 12 meses após o tratamento, o que não ocorreu com a pasta Guedes-Pinto, possivelmente sendo justificada pela grande ação antimicrobiana da pasta CTZ.

Oliveira e colaboradores (2019) relataram três casos clínicos de acompanhamento clínico e radiográfico em pulpotomias realizadas com o uso da pasta CTZ. Notou-se que ela foi efetiva após trinta dias da sua realização, não apresentando fístula, abcesso, mobilidade patológica, reabsorção interna/externa, reabsorção óssea com regressão de lesão e 
remissão da sintomatologia dolorosa.

Oliveira et al. (2021) também relataram um caso clínico de tratamento endodôntico realizado no dente 55 através da utilização da pasta antibiótica CTZ (cloranfenicol, tetraciclina, óxido de zinco) e restauração com resina composta. O paciente foi acompanhado por um período de 3 e 12 meses após o tratamento inicial. Constatou-se que a pasta CTZ estimulou o aumento da velocidade de rizólise em dentes decíduos por meio de reabsorções radiculares patológicas. Porém, como apontado no estudo pelos autores, estudos longitudinais, como ensaios clínicos randomizados, precisam ser conduzidos.

\section{Discussão}

A necessidade da obtenção de alternativas medicamentosas para o tratamento pulpar na dentição decídua de qualidade, tem levado a buscas por alternativas viáveis as práticas convencionais, no qual o profissional odontopediatra deve buscar por conhecimentos de procedimentos mais simplificados que possam alcançar resultados eficazes e satisfatórios (Siegl et al., 2015). Nesse sentido, Luengo-Ferreira e colaboradores (2016), atribuindo a presença de inúmeras foramíneas na furca (região altamente porosa e permeável), promoveram o uso da pasta CTZ como uma forma de promover a comunicação do tecido pulpar com o periodonto, facilitando a difusão dos fármacos. Além disso, eles também relataram, que o sucesso clínico da pasta CTZ é definido com base na combinação de fármacos antimicrobianos que criam uma zona estéril e que com a ação bacteriostática que reduz a carga bacteriana e diminui os microrganismos, modificando sua patogenicidade.

Segundo Amorim et al. (2006), o sucesso do tratamento endodôntico na odontologia pediátrica é influenciado de forma direta justamente pela erradicação dos microrganismos presentes nos canais radiculares infectados. Assim, as espécies individuais da microbiota endodôntica são geralmente consideradas de baixa virulência, mas coletivamente são patogênicas por conta de uma combinação de fatores. Dentro desse contexto, Reis e colaboradores (2016) constataram que as pastas contendo antibióticos, como por exemplo, a pasta CTZ têm demonstrado grande relevância clínica. A tetraciclina é um fármaco que age através de um mecanismo contra um elevado número de bactérias, como as aeróbicas, anaeróbicas facultativas e espiroquetas, microrganismos Gram (+) e Gram (-). O clorofenicol, por sua vez, é um antibiótico bacteriostático de amplo espectro, que também pode ser bactericida em concentrações elevadas ou quando usado contra microrganismos altamente sensíveis. É ativo contra várias bactérias gram-negativas e tem excelente atividade contra todos os microrganismos anaeróbios.

Além disso, a grande maioria das técnicas para realização de um tratamento endodôntico em dentes decíduos, recomenda a utilização de aparatos associados ao isolamento absoluto / total, odontometria, preparo químico-mecânico dos condutos e obturação, que necessitam de instrumentos que nem sempre estão disponíveis no serviço público. Em contrapartida, as técnicas simplificadas consistem na utilização de medicamentos colocados na câmara pulpar, para eliminação de microrganismos presentes (Siegl et al., 2015). Nessa perspectiva, um estudo realizado visando comparar outra pasta obturadora em relação a pasta CTZ, demonstrou resultados com altos índices de eficiência clínica e radiográfica de 80\%, no grupo de molares que receberam a aplicação da pasta CTZ (Luengo-Ferreira et al., 2016).

A pasta CTZ é considerada como uma alternativa ao tratamento endodôntico (Reis et al., 2016). Ela demonstra um vasto quadro de vantagens para seu uso clínico. Dentre elas, recebeu destaque o fato dessa técnica endodôntica oferecer condições para a manutenção dos dentes decíduos na cavidade bucal até sua esfoliação fisiológica, sem provocar prejuízos aos sucessores. Outros pontos positivos relatados da sua utilização foram: a diminuição do custo operatório, a possibilidade de indicação independente do diagnóstico pulpar, a biocompatibilidade apresentada, o alto potencial bactericida e bacteriostático presente, a efetividade terapêutica local e a ausência de instrumentação dos canais. Em suma, a simplicidade na execução da técnica também foi considerada um benefício do seu uso, possibilitando que o procedimento ocorra em uma única sessão (Machado, 2020). 
Depreende-se que a ausência de cooperação por parte de muitas crianças, quando são submetidas ao tratamento endodôntico tradicional dos dentes decíduos, somada a dificuldade na instrumentação desses dentes têm conduzido cirurgiõesdentistas a considerar o uso da pasta CTZ como uma técnica alternativa ao tratamento endodôntico convencional. Além disso, a inserção de um procedimento endodôntico considerado mais acessível e compatível com a realidade do serviço público de saúde facilitaria em demasia o suprimento das necessidades endodônticas de seus usuários pediátricos (Machado, 2020). Todavia, infere-se que apesar dos índices de sucesso clínico da pasta CTZ, que possibilita o desaparecimento dos sinais e sintomas rapidamente, existe uma carência de pesquisas experimentais, laboratoriais e clínicas sobre o tema, que validem sua indicação na prática odontológica e verifiquem a influência do tratamento no desenvolvimento dos dentes permanentes sucessores (Sousa, Duarte \& Sousa, 2014).

\section{Conclusão}

O tratamento endodôntico realizado na dentição decídua apresenta diversas limitações, como a sua anatomia e a dificuldade de execução de um tratamento invasivo em um paciente pediátrico. Por isso, o sucesso e a longevidade do tratamento endodôntico nesses dentes vão depender dos meios que são empregados para a eliminação das bactérias presentes, como por exemplo, pastas obturadoras com capacidades antimicrobianas. Uma das pastas encontradas na literatura que possui esse efeito é a pasta antibiótica CTZ.

Conclui-se que a utilização da pasta CTZ na terapêutica pulpar de dentes decíduos possibilita a manutenção dos dentes tratados endodonticamente, não oferecendo danos aos seus sucessores permanentes, por isso o seu uso se torna uma opção de tratamento pulpar na odontopediatria. Existem poucos estudos sobre a utilização da pasta CTZ com análises mais duradouras, por isso, é necessário um aprofundamento maior nessa técnica, afim de adquirir conhecimentos sobre seus componentes, para obter um maior embasamento científico para sua utilização.

Por fim, deve-se ressaltar que são necessários mais estudos que possam trabalhar a efetividade dessa pasta obturadora a longo prazo, ajudando a desmistificar tal acompanhamento, considerando que a dúvida sobre o uso da pasta CTZ como material obturador no tratamento endodôntico de dentes decíduos se dá pela escassez de artigos e estudos que evidenciem cientificamente sobre sua utilização desde 1964.

\section{Referências}

Amorim, L. F. G., Toledo, O. A., Estrela, C. R. A., Decurcio, D. A. \& Estrela, C. (2006). Antimicrobial Analysis of Different Root Canal Filling Pastes Used in Pediatric Dentistry by Two Experimental Methods. Brazilian Dental Journal, 17 (4), 317 - 322.

Barros, E. V. R. \& Neres, S. D. A. N. Terapia pulpar em dentes decíduos utilizando pasta de CTZ composta de Clorafenicol, Tetraciclina e Óxido de Zinco e Eugenol: uma revisão de literatura. (2017). (Trabalho de Conclusão de Curso apresentado na Faculdade Integrada de Pernambuco para obtenção de título de bacharel em Odontologia). Faculdade Integrada de Pernambuco.

Calixto-Chanca, K., Correa-Olaya, E. I. \& Anchelia-Ramírez, S. H. (2014). Efectividad clínica y radiográfica de dos pastas antibióticas empleadas en necrosis pulpar em niños de un hospital nacional del Perú. Kiru, 11 (2), 115 - 122.

Cappielo, J. (1964). Tratamientos pulpares em incisivos primários. Rev Asoc Odontol Argent.

Cunha, C. B. C. S., Barcelos, R. \& Primo, L. G. (2005). Soluções irrigadoras e materiais obturadores utilizados na terapia endodôntica de dentes decíduos. Pesq. Bras. Odontoped. Clin. Integr., 5 (1), $75-83$.

Fonseca, L. A., Cangussu, R. A., Oliveira, A. S., Pinheiro, S. L., Shitsuka, C. \& Duarte, D. A. et al. Comparação da desinfecção endodôntica de canais radiculares de dentes decíduos utilizando sistemas rotatório e reciprocante: Estudo in vitro. (2020). Research, Society and Development, 9 (8), 1 - 18.

Guedes, C. N. C. S., Moura, M. S., Lopes, T. S. P \& Moura L. F. A. D. (2012). Avaliação Clínica e Radiográfica de Intervenções Pulpares Realizadas com Pasta CTZ na Clínica Odontológica Infantil da UFPI [monografia] Piauí: Universidade Federal do Piauí.

Guedes-Pinto, A. C. (2010). Odontopediatria. 8. ed. São Paulo: Santos.

Guedes-Pinto, A. C. (2016). Odontopediatria Clínica, Artmed, São Paulo. 
Hecksher, F., Vidigal, B., Coelho, P., Otoni, D., Alvarenga, C. \& Nunes, E. (2019). Endodontic Treatment in Artificial Deciduous Teeth through. Manual and Mechanical Instrumentation: A Pilot Study. International Journal of Clinical Pediatric Dentistry, 12 (1), 15 - 17.

Imparato, J. C. P. et al. (2017). Odontopediatria Clínica: Integrada e atual. 1ª ed. Nova Odessa - SP - Brasil: Editora Napoleão (3).

Júnior, A. P. S. (2017). Pastas obturadoras no tratamento endodôntico de dentes decíduos: revisão de literatura. (Trabalho de Conclusão de Curso apresentado na Faculdade Maria Milza para obtenção de título de bacharel em Odontologia). Faculdade Maria Milza.

Lima, V. L. S. N. (2019). Materiais obturadores (Guedes-pinto e vitapex) utilizados na terapia endodôntica de dentes decíduos: revisão de literatura. (Trabalho de Conclusão de curso apresentado na Faculdade Maria Milza para obtenção de título de bacharel em Odontologia). Faculdade Maria Milza.

Luengo- Ferreira, J., Medina, A. R., Montoya, M. E. H., Rosas, C. Y. D., Medrano, L. E. C. \& García, I. T. et al. (2016). Efectividad Clínica y Radiográfica de la Pasta Antibiótica CTZ en Pulpotomías de Molares Primarios. Ensayo Clínico Aleatorio Controlado. Int. J. Odontostomat., 10 (3), 425 - 431.

Luengo-Ferreira, J., Ayja-Jimenéz, S., Carolos-Medrano, L. U., Toscano-García, I. \& Anaya-Álvarez, M. (2019). Clinical and Radiographic Evaluation of Formocresol and Chloramphenicol, Tetracycline and Zinc Oxide-Eugenol Antibiotic Paste in Primary Teeth Pulpotomies: 24 month follow up. Journal Of Clinical Pediatric Dentistry, 43 (1), 16 - 21

Machado, M. K. F. (2020). Emprego da pasta CTZ como material obturador em odontopediatria: revisão de literatura. (Trabalho de Conclusão de Curso apresentado na Universidade Federal do Ceará para obtenção de título de bacharel em Odontologia). Universidade Federal do Ceará.

Moura, L. F. A. D., Lima, M. D. M., Lima, C. C. B., Machado, J. I. A. G., Moura, M. S., \& Carvalho P. V. (2016). Endodontic Treatment of Primary Molars with Antibiotic Paste: A Report of 38 Cases. The Journal of Clinical Pediatric Dentistry, 40 (3), 175 - 177.

Piva, F., Junior, I. M. F. \& Estrela, C. (2008). Antimicrobial activity of different root canal filling pastes used in deciduous teeth. Materials Research, 11 (2), $171-173$.

Oliveira, C. V. R. L., Mota, K. R., Brandão, D. G., Oliveira, G. H. P., Nascimento, P. B. L. \& Marcelos, P. G. C. L. et al (2021). Reabsorção radicular patológica em molar decíduo submetido a tratamento endodôntico com pasta à base de Cloranfenicol, Tetraciclina e Óxido de Zinco (CTZ): Relato de caso Research, Society and Development, $10(1), 1-8$.

Oliveira, M. A. C. \& Costa, L. R. R. S. (2006). Desempenho clínico de pulpotomias com pasta CTZ em molares decíduos: estudo retrospectivo. Revista $R O B R A C, 15(40), 55-63$

Oliveira, S.C. M., Omena, A. L. C. S., Lira, G. A. L., Ferreira, I. A., Imparato, J. C. P. \& Calvo, A. F. B. et al. (2019). Do Different Proportions of Antibiotics in the CTZ Paste Interfere with the Antimicrobial Action? In Vitro Study. Pesquisa Brasileira em Odontopediatria e Clínica Integrada, 19 (1), 1 - 8.

Passos, I. A., Melo, J. M. \& Moreira, P. V. L. (2008). Utilização da pasta CTZ em dente decíduo com necrose pulpar - relato de caso. Odontologia. Clín.Científ.,7 (1), $63-65$.

Pinheiro, H. H. C., Assunção, L. R. S., Silva, L. R., Torres, D. K. B., Miyahara, L. A. N. \& Arantes, D. C. et al. (2013). Terapia endodôntica em dentes decíduos por odontopediatras. Pesq Bras Odontoped Clin Integr, João Pessoa, 13 (4), 351-60.

Raslan, N., Mansour, O. \& Assfoura, L. (2017). Evaluation of antibiotic mix in Noninstrumentation Endodontic Treatment of necrotic primary molars. European Journal of Paediatric Dentistry, (4), 285 - 290.

Reis, B. D. S., Barbosa, C. C. N., Soares, L. C., Brum, S. C., Cecilio, O. L. \& Marques, M. M. et al. (2016). Análise "in vitro" da atividade antimicrobiana da pasta ctz utilizada como material obturador na terapia pulpar de dentes decíduos. Revista Pró-universus, 7 (3), 39 - 42

Rother, E. T. (2007). Revisão sistemática x revisão narrativa. Acta Paulista de Enfermagem, 20 (2).

Santos, C. A. G., Machado, C. A. V., Telles, P. D. S. \& Rocha, M. C. B. S. (2013). Perda precoce de molares decíduos em crianças atendidas na Faculdade de Odontologia da Universidade Federal da Bahia. Odontol. Clín-Cient., 12 (3), 189 - 193.

Siegl, R. M. C., Lenzi, T. L., Politano, G. T., Benedito, M. D., Imparato, J. C. P. \& Pinheiro, S. L. et al. (2015). Two endodontics techniques analysis in primary molars with fistula. Rgo - Revista Gaúcha de Odontologia, 63 (2), 187 - 194.

Silva, R. T. P. \& Silva, E. S. (2018). Utilização da pasta CTZ Em terapia pulpar em odontopediatria: Uma revisão de literatura. (Trabalho de Conclusão de curso apresentado na Faculdade Integrada de Pernambuco para obtenção de título de bacharel em Odontologia). Faculdade Integrada de Pernambuco.

Sousa, P. M., Duarte, R. C. \& Sousa, S. A. (2014). Acompanhamento clínico e radiográfico de dentes decíduos submetidos à terapia pulpar com a pasta CTZ. Pesquisa Brasileira em Odontopediatria e Clínica Integrada, 14 (3), 56 - 68.

Toledo, A. O. \& Massara, M. L. A. (2010). Terapia pulpar em dentes decíduos. In: Toledo OA. Odontopediatria: fundamentos para a prática clínica. Rio de Janeiro.

Toline, C., Bresolin, C. R. \& Shitsuka, C. Tratamento endodôntico mecanizado em dentição decídua. (2021). Research, Society \& Development, 10 (13), 1 - 8. 